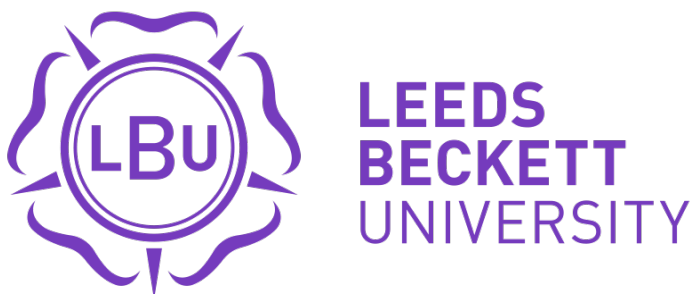

Citation:

Bradley, Q (2018) Neighbourhood planning and the production of spatial knowledge. Town Planning Review, 89 (1). pp. 23-42. ISSN 0041-0020 DOI: https://doi.org/10.3828/tpr.2018.2

Link to Leeds Beckett Repository record:

https://eprints.leedsbeckett.ac.uk/id/eprint/4331/

Document Version:

Article (Accepted Version)

Creative Commons: Attribution-Noncommercial 4.0

The aim of the Leeds Beckett Repository is to provide open access to our research, as required by funder policies and permitted by publishers and copyright law.

The Leeds Beckett repository holds a wide range of publications, each of which has been checked for copyright and the relevant embargo period has been applied by the Research Services team.

We operate on a standard take-down policy. If you are the author or publisher of an output and you would like it removed from the repository, please contact us and we will investigate on a case-by-case basis.

Each thesis in the repository has been cleared where necessary by the author for third party copyright. If you would like a thesis to be removed from the repository or believe there is an issue with copyright, please contact us on openaccess@leedsbeckett.ac.uk and we will investigate on a case-by-case basis. 


\section{Neighbourhood planning and the production of spatial knowledge}

\section{By Dr. Quintin Bradley,}

Leeds Sustainability Institute, School of Built Environment and Engineering, Leeds Beckett University, Leeds LS2 8AG, United Kingdom

q.bradley@leedsbeckett.ac.uk

\section{$\underline{\text { Key words }}$}

Place attachment, neighbourhood planning, participation, spatial knowledge

\section{Abstract}

This paper explores the production of what counts as authoritative knowledge in neighbourhood planning in England. The aim of the paper is to evidence the process through which the intelligibility of place was established in participatory planning in neighbourhoods and to chart the exclusions and exceptions through which spatial norms were produced. It evidences the moderating effect that logics of economic development had in a policy dedicated to the promotion of sustainable development, and, in contrast, it analyses the new expressions of place intelligibility successfully rendered in neighbourhood planning. The paper concludes that the ability of neighbourhood planners to privilege place over logics of development points to a more inclusive and egalitarian approach to the construction of planning knowledge. 


\section{Introduction}

A key driver for the advancement of public participation in town planning has been the need to widen the sources of knowledge and ways of knowing applied to the ordering of space. Where development policy may privilege the supposed objectivity of technocratic rationalism, participation brings other ways of knowing and different types of evidence and methods of evidence gathering to the understanding of place (Davoudi 2015; Natarajan 2017). The challenge for participatory planning has been how to express and enhance the bonds between people and place within development frameworks. Much attention has focused, therefore, on establishing the intelligibility of place representation in relation to economic growth and on defining its appropriate contribution to, and comparative weighting in, land use and development plans.

The policy of neighbourhood planning was launched in England in 2011 as an opportunity for local people to foster a sense of place in development plans in exchange for their support for the allocation of land for new house-building (Stanier, 2014). Neighbourhood planning addressed itself to a localism agenda in which economic development could serve to enhance the values and attachments of place belonging and it offered local citizens the opportunity to achieve some balance between economic, social and environmental sustainability (DCLG 2011). It promised to widen both the sources of knowledge and the ways of knowing incorporated into local development plans.

The aim of this paper is to critically examine the 'rules of formation' for the representation of place in neighbourhood development plan policy (Foucault, 2002/1970: xii). The paper draws on national research studies carried out by the author and other scholars to chart the representations of place scripted by the local citizens compiling a neighbourhood plan, the amendments to these policies made by planning professionals to ensure they complied with statutory development frameworks, and any subsequent changes to the content of the neighbourhood plan brought about through the planning appeal process or through legal action by developers and land owners. The paper is concerned with the construction of 
'authoritative knowledge' in neighbourhood planning policy (Roy 2010: 56), the production of spatial norms, the range of variations on those norms, and the point at which those variations become characterised as deviant. In uncovering this process of normative inclusion and abjection, the paper seeks to contribute to the literature on participative planning and the construction of planning knowledge. It argues that the ability of neighbourhood plans to privilege the intelligibility of place over logics of economic growth provides a new perspective on the unequal conflict over knowledge claims in participatory planning. In particular, it points to the possibility of a more inclusive and egalitarian approach to the construction of planning knowledge.

In the first section, the paper provides the theoretical context for this argument in a discussion of the epistemology of planning, or planning as a way of knowing. It explores the relationship between abstract space and the phenomenology of place and discusses the mechanisms by which the intelligibility of place is established in planning. In the following sections, the paper identifies three processes of exclusion that act to constrain the representation of place in neighbourhood plans. It then turns to a discussion of the successes of neighbourhood plans in establishing new representations of place in development planning. It concludes with an assessment of the impact of neighbourhood planning in enlarging the space of knowledge available to planning policy.

\section{Abstract space and planning knowledge}

Spatial planning has a long-founded concern with the incorporation of local knowledge into technical rationalities (Friedmann 2010; Natarajan, 2017). In its participatory practice, planning suggests that the cognitions and emotions of place attachment can be normalised, and a semblance of equilibrium achieved between market logics and the pursuit of wellbeing (Rutherford \& Rutherford 2013).

This is a process of integration in which a way of being - the phenomenology of emplacement - is brought into dialogue with a way of knowing - the epistemology of planning (Allen \& Crookes, 2009). The resulting assemblage of spatial practices enlarges planning's 'space of knowledge' (Foucault, 2002/1970: xi) at the same time 
as it modifies the perception and material production of place as the object of that knowledge. This process of integration takes place under constraint, as Lefebvre (1991/1974) argues; it is a merger made in the hegemony of abstract space, and the rule of 'abstraction as a codified practice' (Poovey 1995: 9). It conceals potentially irreconcilable differences between the rationality of development and the particularities of place attachment and it serves to distract attention from those expressions of lived space that are rejected and excluded from planning practice.

The knowledge claims of town planning stem from an understanding of space as abstract; as homogenous, continuous and empty. Abstract space provides a conceptual grid that enables phenomena to be 'compared, differentiated and measured by the same yardstick' (Poovey 1995: 9). This notion of functional equivalence provides the rationale for spatial practices that demarcate space into property, submit it to calculation and parcel it into lots for development. Abstract space establishes an epistemology or way of knowing that renders particularities intelligible through generalisation, and through the measurement of norms. It extrapolates a transcendent meaning from statistics and empirically observed facts to establish an incontrovertible and universal narrative (Allen \& Crookes 2009).

The abstraction of space represents more than an ability to generalise and engage in abstract thinking. The concept of abstract space is inseparably associated with the rise of capitalism and the evolution of liberal governmentality (Wilson 2013). It established the legitimacy of commodity production and of commodification. Logics of abstraction were applied to people and behaviours as well as to representations of space, with the effect that use value could be abstracted into exchange value and the products of labour became commodities. In the 1844 Economic and Philosophical Manuscripts, Marx characterised this abstraction as a process of alienation, in which: 'the object that labour produces, its product, confronts it as an alien being, as a power independent of the producer' (Marx 1971/1844:135). This critique of abstraction as alienation was applied to spatial planning by Henri Lefebvre in his key work The Production of Space (1991/1974). He argued that the practice of town planning materially produced space as abstract in order to render it uniform, exchangeable and 
plannable. This production of abstraction stripped lived space of its specific significance and its particular relationship to residence and belonging. As Lefebvre (1991/1974: 52) explained: 'abstract space tends towards homogeneity, towards the elimination of existing differences or peculiarities'. In the abstraction of lived space, daily life was alienated from emplacement; place meaning and place attachment were replaced with 'space planned for production and growth' (Lefebvre 1991/ 1974: 343).

If abstract space is 'the location and source of abstractions' as Lefebvre argued (1991/1974: 348), it is implied by contrast that there exists a real place where 'spatial practice is lived directly' (Lefebvre 1991/1974: 34). In Lefebvre's famous spatial triad this reality appeared in the form of representational or lived space. It was the qualitative element in his three-part dialectic of spatial practices. Lived space 'embraces the loci of passion, of action and of lived situations' (Lefebvre 1991/1974: 42). In advancing this concept Lefebvre reflected a phenomenological concern with emplacement as a condition of being. Phenomenological philosophers regard place as fundamental to what it means to be human. In Being and Time (1962), Martin Heidegger originated the term Dasein - literally translated as 'There Being' - to designate the human condition. Dasein is Heidegger's name for humanity and for the type of emplaced being that humans have, a being-in-the-world, where space and spatiality are conditions of perception, action and knowledge production (Gorner 2007). Human geographers argue that our experience of place is felt 'in the bones' (Tuan 1975: 165). Place is not a backdrop or a setting from which we stand distinct; instead 'people and their worlds are integrally intertwined' (Seamon 2014: 11). In phenomenology, knowledge flows from emplacement rather than from abstraction.

In The Order of Things, Foucault (2002/1966) traced the origin of the dichotomy between phenomenology and abstract thought to the Kantian notion of the knowing subject which, he argued, established humanity with the disciplinary power to award meaning and organise space. In A Critique of Pure Reason Kant (1781/1939) maintained that knowledge of space is a priori; that is, an understanding of abstraction that does not proceed from perception or empirical observation. Knowledge of abstract space is assumed to be a truth that is prior to and independent of practical 
experience. In this way, the epistemology of planning is founded on a repudiation of 'the knower's messy involvement in the factual world of language, life and labour' (Dreyfus \& Rabinow 1982: 32). Kant's philosophy goes further than that, however, to frame experience of place as the abstraction. Since space is homogenous and continuous any representation of place is meaningless unless it applies to space as a whole. To single out the particularities of place is to fail to grasp the unity of space. This leads Kant to make a distinction between the value of concepts and intuitions, where concepts are formed through the reasoned manipulation of abstract thought and intuitions arise from our sense perception of particularities, a sensibility of one aspect only of the whole. Kant's (1781/1939 B:75) well-known axiom that 'thoughts without intuitions are empty, intuitions without concepts are blind' can be applied in spatial planning as the philosophical grounding for participation and community engagement. Planning knowledge stands above the practicalities of experience, and universalises its epistemological discipline by engaging with earthy but limited perceptions from the world of the senses.

\section{$\underline{\text { Local knowledge and emplacement }}$}

The engagement of place-based experience or 'local knowledge' in professional decision-making has been the abiding theme of participatory planning (Mosse 2001). Those who champion participation as an instrument of empowerment challenge the narrowness of the sources of knowledge considered relevant to public policy, the restricted categories of people whose knowledge was valued and the processes by which knowledge is arrived at' (Wainwright 2003: 23). Local knowledge implies an assessment of ends and means that is qualitatively different from the 'objectivity' of deductive reason. It does not depend on abstract thought nor does it proceed from the principle of functional equivalence.

The value attributed to local knowledge in participatory planning draws on a moral register informed by phenomenology's representation of emplacement as a primal human relationship, or as a direct and unmediated feeling for place (Massey 2004). 
Through participation planners seek to acquire the knowledges that people-in-place have of their own lives and their own places' (Schneekloth \& Shibley 2000: 135). The implication that local knowledge is somehow primeval is difficult to sustain without reference to a pre-modern, if not archaic way of life. Heidegger has been criticised for appearing to root his philosophy in a romanticised idyll of Alpine peasantry (Harvey 1996). Lefebvre (1991/ 1974: 41) explicitly associated lived space with anthropology. The notion of an antediluvian epoch when human relations with place were not alienated by technocratic rationalism colours participation in planning with resonances that reflect its colonial roots and postcolonial critiques (Somerville 2016). Public participation becomes the purposeful and selective inclusion of an apparently less sophisticated people, the 'ordinary residents' (Allen \& Crookes 2009: 477), or 'ordinary working class people' (Allen 2009: 53) whose lives are distanced from the epistemic abstraction of planners. The assertion of professional distance between the discipline of abstract space and the sensibilities and perceptions of local knowledge risks addressing citizens, or lay planners, as people who are radically Other. Participation would then be seen to engage citizens in the guise of what the postcolonial theorist Gayatri Chakravorty Spivak (1999: 6) calls the 'native informant'; as Aboriginal or Indigenous guides assisting professional explorers to map a dark continent. This unacknowledged colonialism distorts the critical discussion of participation and community engagement in planning policy.

The consolidation of a professional orthodoxy in planning knowledge (Rogerson, Sadler, Wong \& Green 2010) is maintained by the ordering of a hierarchy of 'spatial cultures' (Porter 2010:1) in which authorised or expert narratives assert dominance over 'lay' discourses of place (Jones, 1995; Parkinson, Scott \& Redmond, 2016). In this order of knowledge, planning interventions must be justified through supposedly objective assessments of need and the assemblage of a robust and value-free evidence base. An apparently linear and unproblematic connection between 'facts' and policy provides the planning profession its cloak of scientific rationality (Davoudi 2015). Trust in the epistemological stability of these facts is cemented in the planmaking process and in its juridical processes of appeal, inspection and examination 
(Aitken 2009). The methodological problems inherent in the selection of evidence and the variations that emerge in the political process of policy making are downplayed. This ordering of planning knowledge reinforces the notion of a clear distinction between expert and local knowledge, and between concepts of abstract and lived space. Spatial practices are dominated by logics of commodity production and exchange (Murdoch \& Abram 2002), and planning policies are required to prioritise the viability of proposed development, and tailor their interventions to safeguard generous profit margins for the developer. The phenomenological challenge of lived space is rendered legible to the logics of development through normative expressions of amenity, heritage and design. These planning policies effect a translation from phenomenology to the technical rationality of abstract space in an enforcement of conformity that Foucault termed biopower, or the exercise of authority through qualitative experience. To govern in this way, Foucault said, it was necessary that: 'regulatory measures must be introduced to establish an equilibrium, maintain an average, establish a sort of homeostasis, and compensate for variations' (Foucault 2004: 245-246). Normative planning concepts such as 'strong sense of place' or 'local character and history' (DCLG 2012 paragraph 58) enable an acceptable range of variations of place representations, but also a point at which the boundary of acceptability is deemed to be exceeded. Expressions of place attachment that go beyond this range of acceptability can be judged to have crossed a line between place distinctiveness and the irrationality of place protection. If they are no longer in conformity with the prevailing logics of development they can demonstrably be evidenced as abnormal and subsequently excluded from consideration (Dreyfuss \& Rabinov, 1982: 196; Huxley, 2006; Mayes, 2015).

These dynamics of inclusion and abjection appear in participatory planning as a conflict between social constructions of knowledge mediated by a yawning inequality in power relations. The guarded inclusion of lay discourses that give primacy to place as 'directly lived through its associated images and symbols' (Lefebvre 1991: p.39) disrupts the sedimentation of authoritative knowledge (Roy 2010: 56). In the epistemology of participatory planning, the 'rules of formation' become matters of 
biopolitical tension (Foucault, 2002/1970: xii). The assemblage of spatial practices that emerges may enlarge the space of inclusion in planning, and it is as important to identify the accepted variations on the norm as it is to observe the point at which those variations are considered deviant.

To explore this further, the paper now turns to a study of neighbourhood planning in England, a policy unusual for its declared intent to mobilise the attachments of lived place to enlist citizen consent for economic development. Neighbourhood planning provided a regulated environment within which place attachment could be expressed in planning policy and made subject to the imperatives of sustainable development. Scrutiny of the planning policies produced by neighbourhoods under this regime can evidence the rules of formation for the normalisation of place in planning knowledge.

\section{Neighbourhood Planning Research}

The policy of neighbourhood planning, introduced in England by the Localism Act (2011), purported to enable local communities to reconcile the attachments of place with the requirements of development planning. The government guidance for neighbourhood planning explained:

People around the country value and love the places they live in. To make sure that you and your neighbour have the community you aspire to, the government has given you new legal powers and new opportunities to preserve what you like and change what you don't like about the city, town or village you live in (DCLG 2013: p.4).

A neighbourhood plan could be initiated by a Town or Parish Council or, in urban areas, by a community group establishing a Neighbourhood Forum. These 'qualifying bodies' could apply to the local planning authority to be designated as a neighbourhood area. They were responsible for assembling an evidence base from community engagement, and for writing planning policy, and the resulting neighbourhood plan 
went through a statutory consultation process and was formally examined. To win community support, the neighbourhood plan must be approved in a local referendum and receive more than 50 per cent of the vote of those registered and taking part in the ballot. Once approved in referendum, the neighbourhood plan became part of statutory development policy and was used to help determine planning applications in the locality (Brownill \& Bradley 2017; Bradley 2015; Parker, Lynn, \& Wargent 2015; Wills 2016).

Neighbourhood plans, or to give them their full significant title, Neighbourhood Development Plans, were brought in as part of a radical programme of spatial deregulation that aimed to accelerate economic growth. Neighbourhood planning powers were set out in a new National Planning Policy Framework that enshrined the presumption of sustainable development binding on local authorities and their neighbourhoods, conceived as a presumption in favour of economic growth - unless its adverse impacts 'significantly and demonstrably outweigh the benefits' (DCLG 2012: paragraph 14). Neighbourhood plans had to be in general conformity with the strategic policies drawn up by unitary and district authorities. They could not promote less development than stipulated in the Local Plan or undermine its strategic policies and they had to have regard to national policies and be compatible with EU obligations. They had to contribute to the achievement of sustainable development, defined in its economic, environmental and social aspects, but 'plan positively to support local development' (DCLG, 2012, Paragraphs 15-16).

By the autumn of 2017, five years after the launch of the policy, there were 2,183 neighbourhood plans under production, while 337 had been successful at referendum and had been made part of the statutory planning framework across 15 per cent of England covering ten million people (Brownill \& Bradley, 2017). The geographical spread of neighbourhood plans was particularly uneven and mapped to spatial inequalities only partially off-set by state grants and support from municipal planning authorities. While 23 per cent of plans were in the least affluent urban neighbourhoods, the majority were produced by rural parish councils and market 
towns in the south of the country under pressure from development and economic growth (Parker \& Salter, 2016).

The data for this paper comes from a desk top analysis of 50 neighbourhood plans that were successful at referendum between 2016 and 2017 supplemented with field research, including focus groups and interviews carried out between 2012 and 2016, with 300 participants in a further 30 neighbourhood planning groups (Bradley, 2015). This data is contextualised with reference to the peer reviewed literature on neighbourhood planning, and especially an updated analysis of surveys carried out with 52 participants in neighbourhood plan groups (Parker et al, 2014; Parker \& Wargent, 2017). It also draws on examination reports which evidence the amendment and deletion of neighbourhood policies on place and considers the outcomes of legal judgements, reports from appeals against refusal of planning permission, and rulings from the planning inspectorate and the Secretary of State on appeal decisions.

The analysis that follows identifies three dynamics of exclusion that operated to constrain the representation of emplaced knowledge in neighbourhood plans. The selection of neighbourhood plans for particular analysis and the use of excerpts from interviews carried out by the author are provided to corroborate and provide more qualitative expression to themes evidenced widely in this national research and discussed in detail in the text. The analysis then considers the variations on the norm of place representation in neighbourhood planning policy that significantly expanded the boundary of acceptability. The case studies in this section are drawn from the body of neighbourhood planning policy up to 2017 , as those that were either the first to enact a specific development regulation or were successfully defended in legal action and written into case law (PAS, 2015). The selection of this sample enables examination of place representations that have proved innovative and challenging to the development market and contributed to the revision of the rules of formation of planning knowledge. 
The alienation of neighbourhood planning

Neighbourhood planning was intended to bring local knowledge into the development process and to give citizens and local communities responsibility for statutory decisions over land and property rights (Brownill \& Bradley 2017). The first stage in the neighbourhood planning process was for the town or parish council, or designated neighbourhood forum to gather a wide range of local views on place; assembling from popular consultation a mental map of place meanings, associations, and memories. A steering group or sub-committee would then attempt to marshal these feelings for place into potential planning policies that reflected the presumption in favour of sustainable development in the national planning framework. The first challenge they encountered was in the collision of two distinct sets of knowledge. There was little common ground in language or understanding between an experiential feeling for place and the technical rationalism of planning policy. Citizen planners engaged in neighbourhood planning had to learn to translate their direct experience of the particularities of place into an epistemology founded on abstraction.

Neighbourhood planning absolved professional practitioners from the need to acquire local knowledge. In awarding statutory planning powers to citizens and communities, it required locals to adopt professional methodologies to achieve acceptance (Mosse 2001). This was a form of cultural transference in which citizens achieved the status of (lay) planners but their successful incorporation in the profession reinforced the universality of abstract rationality and underlined the exclusion of other spatial cultures (Porter 2010). To establish the grounds of intelligibility of local knowledge, citizen planners had to adopt an orthodoxy established by professional expertise, and their mastery of this technical lore provided them with limited social recognition (Mayes 2015). In seeking to represent the particularities of place they had to submit local knowledge to a growth-oriented planning culture and adopt a way of knowing and ways of communicating that were alien to an understanding of lived space (Aitken 2009). 
In the public consultation carried out for a neighbourhood plan in Clayton-le-Moors and Altham, near Accrington in the urban north of England, residents were concerned about dog fouling, access to public transport, young people's services, schools, policing, as well as employment and adequate housing. Few of these issues were amenable to solution through a national planning framework focused on land use deregulation and free market liberalism (Bradley, 2016). The forum received advice from the advocacy service Planning Aid, as well as support from planners in the local authority but their initial problem was simply in understanding the language that planners used. The chair of the neighbourhood forum explained:

Unless you've worked in local government, I don't think you can get your head round that sort of thing because they can only talk in one way, so they talk at a level that's foreign to the normal public and that's something we've tried to get away from, but it is very difficult.

As they attempted to convert community issues into planning policy, the planning officers advised on the technical drafting of these representations of place. For the chair of the neighbourhood forum this process of translation into planning policy involved the sacrifice of important local concerns experienced as a loss of authenticity.

There were rules to follow and those rules meant that this and that had to be thrown out. It didn't matter if the baby went with the bath water.

The solution adopted by the forum was to separate land use policies from community aspirations, and to package these separately as local projects. This distinction between planning policies and projects was first established by Exeter St James, an urban neighbourhood plan that went to referendum in 2012. The inclusion of community projects in the plan provided a means to address some of the concerns raised by residents that were not amenable to planning solutions. The first community project put into action by the Exeter St. James forum involved the setting up a community benefit society to take ownership of a neglected urban green space. This was 
resourced by volunteer labour, and depended on limited supplies of social capital. For more disadvantaged neighbourhoods the exclusion of community concerns from statutory planning policy underscored their feeling of marginalisation, and reminded them forcibly of the shrinkage of the space of public responsibility. Clayton-le-Moors and Altham neighbourhood forum had to reconcile themselves to a plan that was in two halves, with community concerns separated from statutory land use policies and relegated to the status of a wish-list. The chair made clear which section of the plan had the most value for the neighbourhood:

There's got to be the sterile language and then there's the other bit we need to tag on, and show people yes, this is what you said you want, this is what we've put in the plan, this is what we want to do. And I think that will be the more interesting part and I hope that's the part that people will take on board, knowing that they had very little influence over planning issues but the other part is theirs.

The 'sterile' language of planning policy was contrasted with the immediacy attributed to the residents' experience of place. This contrast between abstract space and the particularities of place was sharpened by the contradictions within the design of neighbourhood planning policy. In order to be successful the plan needed to be agreed by popular referendum. There was, therefore, pressure on the neighbourhood planning group to demonstrate that the views expressed by the community had been represented in the neighbourhood plan, in order to win support from constituents at the referendum. If they could not translate those place-based experiences and values into planning policy, and into a distinctive set of projects, the neighbourhood plan would appear alien to the community. The product of the community would confront it as 'a power independent of the producer' as Marx originally argued (1971/1844:135). 
Neighbourhood planning and the logic of development

Research with neighbourhood planning groups has demonstrated the barriers encountered by neighbourhoods in planning for place attachment in a regulatory environment focused on economic development (Parker et al, 2014; Parker \& Wargent, 2017). Neighbourhood groups were dependent on planning professionals for the skills and expert knowledge required to write policy that would comply with the regulatory requirements. Using the financial support available to them from government, the majority of groups commissioned private planning consultants to help them draw up suitable policies. In the professional scripting of policy that followed, many neighbourhood participants complained that place-making concerns identified as important in community consultation were excluded from the final plan on the recommendation of local authority officers and consultants. Some place representations were deemed not to meet the requirements of land use planning and therefore fell outside the remit of neighbourhood powers. Others were omitted because the phrasing was unclear or they were insufficiently evidenced and might then fail to stand-up to legal challenge from developers (Parker, Lynne \& Wargent 2015).

The formal examination of a neighbourhood plan by an independent planning consultant appointed by the local planning authority proved the stage in the process when plans were most often amended to establish their conformity with the logics of development (Murdoch \& Abram 2002). The examination was the final stage before referendum and followed a statutory six-week period of public consultation. The examiner, who must be independent of the local authority and have appropriate qualifications and experience, was tasked with assessing whether the neighbourhood plan met the basic conditions of statutory policy and had been prepared in accordance with the regulations. The examiner could recommend either that the plan should proceed to referendum, or proceed subject to modifications, or that the plan should not go to referendum on the basis that it did not meet the legal requirements (Town and Country Planning Act 1990 Paragraph 8 of Schedule 4B as amended). 
At the point of examination, nearly all neighbourhood plans were amended and about half had policies deleted on the recommendation of the examiner (Parker, Salter \& Hickman 2016). Prior to 2016, however, only three plans had failed examination. The neighbourhood plan for Dawlish was produced in 2012 before the regulations governing the process were published and was never expected to pass. More striking was the failure of the Slaugham neighbourhood plan, and its pioneering Community Right to Build orders in January 2014, where the examiner found its housing site allocations were not compatible with EU regulations. The Coton Forward plan for an estate near Coventry failed examination on the grounds that it contained two highways policies that were outside the scope of neighbourhood planning. The local authority revised the plan to exclude these policies and Coton Forward went to successful referendum in October 2015. So the flurry of neighbourhood plans failing examination in 2016 raised the question whether examiners were now setting a higher bar for the technical detail expected in citizens' planning. In Planning magazine (September 9, 2016, page 9), examiner Nigel McGurk was quoted saying it was 'inevitable that one or two will fail as communities try to push the envelope, or lack sufficient understanding of what a neighbourhood plan can achieve'. The neighbourhood plan for Storrington, Sullington and Washington, near Horsham in West Sussex, failed examination in March 2016 because its site allocation policies did not contribute to sustainable development, due to concerns over the adequacy of the supporting criteria and evidence base. In South Oxfordshire, Berinsfield neighbourhood plan and neighbourhood development orders failed examination in May 2016, principally on the grounds that they did not have regard to national policy relating to green belt. The neighbourhood plan for Wantage, in the Vale of White Horse, Oxfordshire, failed examination in August 2016, because it was overly focused on protection of environmental assets. Arguably, though, the highest profile failure was a neighbourhood plan that passed examination, although with major amendments. The examination of the neighbourhood plan for Swanwick, in Amber Valley, Derbyshire, called for the deletion of several key policies including the aims and objectives agreed by the parish. Swanwick parish council felt that the deletions meant that the plan no longer represented the aspirations and expectations of the 
community. When Amber Valley made the amendments and pushed ahead with the referendum, the parish council campaigned against it and the neighbourhood plan was defeated by an $85 \%$ 'no' vote in October 2016. Less dramatically, the parish council of Alrewas, in Litchfield, withdrew their neighbourhood plan from referendum in February 2016, after the examiner recommended the deletion of policies felt to be crucial in addressing issues identified by the community.

It is worth exploring in more detail one of these high-profile neighbourhood planning 'failures', that of Wantage, in South Oxfordshire. Wantage is a market town with a population of 11,000 situated near the North Wessex Downs Area of Outstanding Natural Beauty (ANOB). A rare chalk stream, the Letcombe Brook, flows through the centre of the town. The town council had launched its plan-making process with a series of public meetings and a steering group held a number of further consultation events, sending questionnaires and newsletters to every household, with email updates, website information and exhibitions, trying to build up an understanding of the place and its residents' concerns. Following a further statutory consultation period, the draft Wantage neighbourhood plan was submitted to examination. On 30 July 2016 the experienced independent examiner John Parmiter recommended that the Wantage plan should not proceed to referendum because it did not meet the basic conditions. His view was that the plan did not promote sustainable development and that, instead, it proposed 'extensive protectionist policies' (Parmiter 2016: 9). One of the central policies in the Wantage neighbourhood plan was the proposal to establish a green infrastructure network; a series of 26 green spaces linked by footpaths, cycleways and bridleways with the focus on the conservation of the rare chalk stream and the biodiversity of the ANOB landscape (Wantage Neighbourhood Plan 2016). The examiner pointed to numerous shortcomings in the evidence presented to support this policy and concluded that the plan was 'overly focused on protection of the locality's many features, too often without sufficiently robust evidence to do so' (Parmiter 2016: 14). The unintentional inference of this statement was that a green infrastructure network would have been deemed protectionist even if the evidence had been sufficient. There is no intention to criticise this examination judgement, but 
it is revealing in that it appears to establish a boundary of acceptability in the order of knowledge of neighbourhood planning. Parmiter's judgement confirms that policies to conserve and enhance place distinctiveness may be acceptable only when their impact is significantly outweighed by policies enabling development. As the examiner acknowledged, however, there was little scope in Wantage for allocating land for housing because, due to extensive previous development, 'there is little room left to shape the plan area' (Parmiter 2016: 14). In these circumstances, it could be argued that seeking to contain further expansion of development, and aiming to protect green space and environmental assets were not protectionist policies. Instead, it could be maintained that they were compatible with the promotion of sustainability and wellbeing.

\section{Neighbourhood planning and the threat from developers}

The enforcement of norms through exclusions during the neighbourhood plan examination process threatened the light-touch regime promoted by government to secure the engagement of communities in development planning. The increasingly rigorous policing of neighbourhood plans was not a quirk of the examiners, however; it was a consequence of a deepening conflict between neighbourhood plans and the development industry (Parker, Salter \& Hickman 2016). Major house-builders had sought to overturn the results of neighbourhood plan referenda through judicial review and had appealed against planning decisions made in accordance with neighbourhood development policies. In March 2016 the housing and development policies in the Haddenham neighbourhood plan in Aylesbury Vale were quashed in the face of a High Court hearing brought by property company Lightwood Strategic Ltd, thus overturning the decision of its examination and the outcome of its successful referendum. The neighbourhood plan for Loxwood, near Chichester, had been subjected to a series of legal challenges from Crownhall Estates since 2014, with its July 2014 referendum result overthrown, its May 2015 referendum postponed, and its final public endorsement in July 2015 unsuccessfully contested in the High Court in January 2016. Henfield's neighbourhood plan was quashed by the courts in October 
2016, when Stonegate Homes and Littleworth Properties won a judicial review on the grounds that the making of the plan was incompatible with EU regulations. This legal action focused on the criteria and evidence used to make housing site allocations, and the result underlined the need to ensure that policies in neighbourhood plans were robust and founded on unimpeachable process. This had the effect of making citizen planners more dependent on the technical advice of the local planning authority and of private planning consultants (Parker \& Wargent 2017), and this assistance was often guided by the need to avoid anything likely to lead to developer challenge. The effect of this risk-averse approach was to encourage a climate of self-censorship among neighbourhood groups and further alienate those citizens who sought to use neighbourhood planning to enhance their sense of place. In the neighbourhood forum of Friends of Fishwick and St. Matthews in Preston, in the north of England, the former secretary explained the impact of this increasingly restrictive policy regime:

We wanted the final document to reflect the fact that it was produced by a community group. We then slowly realised that in order to pass the examination stage, we had no choice but to comply with protocols, which included using planning speak throughout. The final product ended up looking more like a corporate document.

This perceived gap between the function of planning policy and the place-based needs of residents was not healed by the neighbourhood planning process. Two years after the Fishwick and St. Matthews plan was approved at referendum, and became part of the statutory development framework, the former secretary of the neighbourhood planning group saw no change either in the place she lived, or in the responsiveness of planning to local needs.

I personally see no obvious change as a result of the neighbourhood plan. Planning policy I would say has so far remained as inflexible and geared to support developers as it has always been. I would therefore acknowledge the relationship between community ideas and planning policy as a tension, or a 
struggle, and based on our experience I would argue that planning policy is winning (at the moment).

The rules of formation of neighbourhood planning knowledge appeared to tighten under pressure from the threat from the development industry. The antagonism of the major house-builders can be explained conversely, however, by the extent to which neighbourhood planners had already successfully blurred these rules. The next section discusses how the norms of place representation were changed under neighbourhood planning and how new variants of place representation became acceptable planning practice.

\section{Neighbourhood planning and place knowledge}

The most popular policy in neighbourhood plans was the promotion of local distinctiveness and place identity (DCLG 2015). Neighbourhood plans attempted to evoke a sense of place through policies on design, green space, recreation, natural and historic environment and the identification of community assets. Constrained by the privileged role given to housing growth in the National Planning Policy Framework (DCLG 2012), neighbourhood plans required developers to adapt their proposals to respect local topography, views and aspects, and the character, distinctiveness, scale and density of the neighbourhood. Where neighbourhood plans allocated specific sites for new housing, they set out design principles to foster development that complemented the neighbourhood in materials, layout, amenity and the conservation of natural features. Nearly all neighbourhood plans designated new protected green spaces, and rural plans in particular assembled policies to protect and enhance biodiversity, maintain settlement boundaries and guard against infringements of open countryside. They sought to protect community facilities, sports fields and allotments, and improve pedestrian access and cycle routes. To pass examination the weight given to place distinctiveness in neighbourhood plans had to be couched in terms of the presumption in favour of sustainable development and include expressions of support for housing growth, albeit as a managed process of change. In scripting 
policies on housing delivery neighbourhood planners found unforeseen opportunities to champion local needs and to express a sense of place. Contrary to the appetite of the volume house-builders for green field sites, neighbourhood plans prioritised small, previously developed or brownfield land, where development would cause minimum disruption to environmental quality and local character (Bailey 2015). They were especially concerned to deliver affordable homes to meet local housing need and favoured resident-led approaches in custom-build and community land trusts that might lock-in affordability for the future (Bradley \& Sparling 2016). The selection of specific sites for housing, the specification of the size, mix and design of the development, and policies regulating its affordability and relation to local need were evaluated and rationalised in reference to assertions of place attachment (Bradley 2017). Neighbourhood planning appeared to author a new mode of housing delivery that was sensitive to place identity and challenged the norms of the speculative builders, and was sometimes explicitly in opposition to the corporate model of housebuilding. There is now a considerable body of literature on these housing policies but two examples may be useful to illustrate this impact in more detail.

The neighbourhood plan for Tattenhall, a village of around 1000 homes in rural Cheshire, was one of the first to successfully defend its place representations from legal challenge by developers. The neighbourhood plan constructed an evidence base from assertions of local character and heritage to justify a limit on the number of homes that could be built in the village. The cap of no more than 30 homes would allow 'a vibrant and distinctive village to evolve and expand whilst retaining its unique character' (Tattenhall \& District, 2013: p.8). The Tattenhall neighbourhood plan was approved at examination and was successful at referendum in September 2013 on a convincing 52 per cent turnout. Legal action by house-builders Barratt Homes and Wainhomes was dismissed by $\mathrm{Mr}$ Justice Supperstone who ruled that the neighbourhood plan had established its case for housing development at a scale that reflected the existing character of the area'. 
The neighbourhood plan for St. Ives, in Cornwall, with a population of 11,000 , addressed the problems of housing affordability in a globally recognised holiday destination that receives tens of thousands of visitors every year. Expressing the increase in holiday homes and second homes as a threat to the town, the plan successfully argued that St Ives 'needed to be nurtured, protected and guided into the future' and 'the best people to do this are those who live here' (St Ives Town Council, 2015: p.3). The neighbourhood plan introduced restrictions to ensure new homes could only be used as the owner's primary residence and mandated that 40 per cent of all newly developed housing should be affordable and reserved for local people. The policy was approved by the Examiner, and subsequently upheld in the High Court, on the grounds that: 'the restriction of further second homes does in fact contribute to delivering sustainable development' (McCann, 2015: p.30). Once established in planning policy, neighbourhoods up and down the coast from St Ives followed suit and implemented plans to encourage affordable homes for primary residence, justifying their market interventions in the name of place distinctiveness.

Neighbourhood planning authored a spatial practice of housing delivery that resonated with emplaced perceptions of local knowledge. In their housing policies more than in any other aspect of plan-making they 'demonstrated a different way of "doing" planning, emphasising [...] the sights, smell and feel of a neighbourhood as well as making provision for health and happiness rather than focusing solely on the built environment' (Field \& Layard 2017: 107). They showed that logics of development could be brought into balance with lay discourses and that planning in its most abstract conception of spatial practice could nevertheless evoke the particularities of place. Where neighbourhoods like Wantage encountered an inflexible divide between acceptability and abjection, plans such as Tattenhall and St. Ives established new norms of place intelligibility, expanding the space of knowledge in participatory planning and changing the rules of formation.

In successfully adapting an expert discourse of planning to privilege the representation of place neighbourhood planners had to become proficient in the production of abstract space, the object of speculative housing development; space divided into 
subdivisions and plots, intelligible in its exchange value and its contribution to commercial expansion. It could be argued, echoing Aiken (2009: 63), that they were 'complicit in the social control to which they were subjected'. Citizen planners had to accede to technocratic procedures of evidence gathering and conceptual deduction. They then attuned abstractions to express the particularities of place. In doing so, they made lived experience central to their spatial practice. These achievements came despite the pressures to avoid risk, to keep to the norm and stick to the script (Parker, Lynn \& Wargent 2015). Their ability to intervene in the logics of development and to direct sustainable development towards place attachment points more to the 'autoproduction of knowledge' in neighbourhood planning (Roy 2009: 168) or the attainment of what Appadurai (2001: 35) called 'governmentality from below'. In asserting a privileged claim for place neighbourhood groups exerted a new productive power in the authoritative knowledge of planning.

The establishment of a new normal in policies for housing delivery demonstrates that local knowledge cannot be treated as Other, as if it was an attribute of a more primitive way of being. For Lefebvre, abstract and lived space were not dichotomous, or poles apart, they were moments in a unity of spatial practice. 'The perceivedconceived-lived triad (in spatial terms: spatial practice, representations of space, representational spaces) loses all force if it is treated as an abstract "model",' Lefebvre wrote (1991/1974: 40). He argued instead that there was movement between the three and he sought to 'rediscover the unity of the productive process' (Lefebvre 1991/1974: 42). This epistemological unity did not represent consensus or harmony, but the recognition of difference and productive conflict in the knowledge applied to space and places (Buckley \& Strauss 2016).

The rationality of abstract space dominates the productive process, and it establishes the rules of knowledge formation in its image. It dispossesses the space of lived experience and renders place conditional: a colonised subsidiary of the technocratic paradigm (Wensing \& Porter 2016). The practices of neighbourhood planning give us a rare glimpse behind this hegemony of abstraction, to spatial practice as a unity of 
moments, in which we find the abstract and the particular: concepts, perception and emotions in progressive tension. In neighbourhood planning we are reminded that sustainable development too should be understood as a dialectical triad of spatial practices. The environmental, the social and the economic exist at once and in each other at all times. The pursuit of participatory planning declares an equality of 'spatial cultures' and signals their interdependent coexistence (Porter 2010: 1). As Kant said (1781/1939 B:75): 'thoughts without intuitions are empty, intuitions without concepts are blind'.

\section{Conclusion}

Participatory planning practice has been seen as a touchstone for the ability of technocratic knowledge to accommodate lay perspectives of lived space. The incorporation of place-based knowledge in development planning becomes integral to the epistemology through which abstract space is produced. The aim of this paper was to evidence the rules of formation through which the intelligibility of place attachment was established in neighbourhood planning, a participatory practice in England at the juncture of lived and abstract space. In its study of the policy the paper evidenced the incorporation and colonisation of local knowledge by an otherwise technocratic programme dedicated to economic growth. Many neighbourhood plans went through a process of normalisation to ensure the plan complied with the regulatory framework. The final plan was very distant from the residents' initial expressions of place attachment and had been, in cases, rendered unrecognisable and alien. Despite this, and in the face of this work of domination, neighbourhood plans successfully pushed the boundaries of authoritative knowledge in planning. They established new norms in the spatial practices of house-building and expanded the space of knowledge allotted to the representation of place in participatory planning. In doing so they asserted the unity of the environmental, social, and the economic in sustainable development and rendered the particularities of place intelligible in a rationality of abstraction. Through neighbourhood planning we are reminded of the diversity but also of the interdependence of spatial cultures and the potential for a planning practice that is founded on equality and not abjection. 


\section{$\underline{\text { Sources }}$}

Aiken, M. (2009) Wind Power Planning Controversies and the Construction of 'Expert' and 'Lay' Knowledges. Science as Culture; 18:1, 47-64

Allen, C. (2009) The Fallacy of "Housing Studies": Philosophical Problems of Knowledge and Understanding in Housing Research. Housing Theory and Society; 26 (1) $53-79$

Allen, C. \& L. Crookes (2009) Fables of the reconstruction: a phenomenology of 'place shaping' in the North of England. Town Planning Review, 80 (4-5):455-480 Amin, A. \& N. Thrift (2002) Cities: reimagining the urban. Cambridge. Polity Press Appadurai, A. (2001) Deep democracy: urban governmentality and the horizon of politics. Environment \& Urbanisation. Vol. 13 (2): 23-43

Bailey, N. (2015): Housing at the neighbourhood level: a review of the initial approaches to neighbourhood development plans under the Localism Act 2011 in England, Journal of Urbanism: International Research on Placemaking and Urban Sustainability, Vol. 10 (1): 1-14

Bradley, Q (2017) Neighbourhood planning and the impact of place identity on housing development in England. Planning Theory \& Practice. Vol.18 (2): 233-248 Bradley, Q. (2016) The patchwork politics of sustainable communities. In: Dastbaz, M., Gorse, C. (eds.) The Selected Proceedings of the International Conference on Sustainability, Engineering and Ecological Design for Society (SEEDS). London. Springer.

Bradley, Q (2015) The political identities of neighbourhood planning in England. Space and Polity. Vol.19 (2): 97-109

Bradley, Q. \& Sparling, W. (2016) The Impact of Neighbourhood Planning and Localism on House-building in England. Housing, Theory and Society, Vol. 34 (1): 106-118 Brownill, S. \& Q. Bradley (2017) Localism and Neighbourhood Planning: power to the people? Bristol. Policy Press.

Buckley, M. \& K. Strauss (2016) With, against and beyond Lefebvre: planetary urbanisation and epistemic plurality. Environment and Planning D: Society and Space; Vol. 34 (4) 617-636 
DCLG (2011) Localism Bill: neighbourhood plans equalities impact assessment. London. Department of Communities \& Local Government.

DCLG (2012) National Planning Policy Framework. London. DCLG

DCLG (2013) You've got the power. A quick and simple guide to community rights. London. DCLG

DCLG (2015) Notes on Neighbourhood Planning 16. London. DCLG

Davoudi, S. (2015) Planning as practice of knowing. Planning Theory. Vol. 14 (3): 316331 ,

Dreyfus, H.L. \& P. Rabinow (1982) Michel Foucault: beyond structuralism and hermeneutics. Brighton. The Harvester Press.

Field, M. \& A. Layard (2017) Locating community-led housing within neighbourhood plans as a response to England's housing needs. Public Money \& Management. Vol. 32 (2): $105-112$

Friedmann, J. (2010) Place and Place-making in cities: a global perspective. Planning Theory \& Practice. Vol.11 (2): 149-165

Foucault, M. (2002) [1966] The Order of Things. Abingdon. Routledge

Foucault, M. (2004) Society must be defended. Lectures at the College de France. Trans.

D. Macey. London. Penguin

Harvey, D. (1996) Justice, Nature and the Geography of Difference. Oxford. Blackwell Publishing

Huxley, M. (2006) Spatial rationalities: order, environment, evolution and government. Social \& Cultural Geography. Vol. 7 (5): $771-787$

Gorner, P. (2007) Heidegger's Being and Time. An Introduction. Cambridge. Cambridge University Press.

Lefebvre, H. (1991) [1974] The Production of Space. Oxford. Blackwell Publishing.

McCann, D. (2015) Independent Examiners Report on the St. Ives Neighbourhood Development Plan. Cornwall. Penwith County Council.

Massey, D. (2004) Geographies of Responsibility. Geografiska Annaler; 86 B (1): 5-18

Mayes, C. (2015) The biopolitics of lifestyle: Foucault, ethics and healthy choices. London. Routledge 
Mosse, D. (2001) 'People's Knowledge', Participation and Patronage: operations and representations in rural development. In: Cooke, B. \& U. Kothari (eds.) Participation: the new tyranny. London. Zed Books.

Murdoch, J. \& S. Abram (2002) Rationalities of Planning: development versus environment in planning for housing. Aldershot. Ashgate

Natarajan, L. (2017) Socio-spatial learning: a case study of community knowledge in participatory spatial planning. Progress in Planning; 111: 1-23

PAS (2015) Neighbourhood Planning Issues. London. Planning Advisory Service.

Parker, G., T. Lynne, M. Wargent \& Locality (2014) User experience of neighbourhood planning in England research. Reading. University of Reading.

Parker, G., Lynn, T. and Wargent, M. (2015) 'Sticking to the script? The co-production of Neighbourhood Plans', Town Planning Review, 86 (5): 519-536.

Parker, G., Salter, K. \& Hickman, H. (2016) Caution examinations in progress: the operation of neighbourhood development plan examinations. Town and Country Planning, 85 (12): 516-522

Parker, G. \& Wargent, W. (2017) Participant experience of neighbourhood planning in England. Working papers in real estate and planning 01/17. Reading. Henley Business School, University of Reading.

Porter, L. (2010) Unlearning the Colonial Cultures of Planning. Farnham. Ashgate Rogerson, R., S. Sadler, C. Wong \& A. Green (2010) Planning sustainable communities - skills and learning to envision future communities: an introduction. Town Planning Review, 81 (5): 505-521

Roy, A. (2010) Poverty Capital: microfinance and the making of development. Abingdon. Routledge

Roy, A. (2009) Civic Governmentality: the politics of inclusion in Beirut and Mumbai. Antipode. Vo.41 (1): 159-179

Rutherford, S. \& P. Rutherford (2013) Geography \& Biopolitics. Geography Compass, 7/6: 423-434

Schneekloth, L. \& R. Shibley (2000) Implacing architecture into the practice of placemaking. Journal of Architectural Education. Vol. 53 (3): 130-140. 
Seamon, D. (2014) Place attachment and phenomenology: the synergistic dynamism of place. In: Manzo, L. \& P. Devine-Wright (eds.) Place attachment: advances in theory, methods and applications. London. Routledge: 11-20

Somerville, P. (2016) Understanding community. $2^{\text {nd }}$ edition. Bristol. Policy Press.

Stanier, R. (2014) Local Heroes: Neighbourhood Planning in Practice. Journal of Planning and Environment Law. Issue 13. Thomson Reuters (Professional) UK Limited Tattenhall \& District (2013) Tattenhall Neighbourhood Development Plan. Cheshire. Tattenhall Parish Council

Wainwright, H. (2003) Reclaim the State: experiments in popular democracy. London, Verso.

Wantage Town Council (2015) Wantage Neighbourhood Plan. Wantage, Oxfordshire. Wantage Town Council.

Wensing, E. \& L. Porter (2016) Unsettling planning's paradigms: towards a just accommodation of Indigenous rights and interests in Australian urban planning? Australian Planner. Vol.53 (2): 91-102

Wills, J. (2016) Emerging geographies of English localism: The case of neighbourhood planning. Political Geography 53: 43-53

Wilson, J. (2013) 'The Devastating conquest of the lived by the conceived': the concept of abstract space in the work of Henri Lefebvre. Space and Culture, 16: 364-380

\footnotetext{
i Barratt Homes \& Wainhomes Developments v Cheshire West \& Chester Borough Council, Stephen Robinson \& Tattenhall \& District Parish Council [2014] EWHC 1470 Q.B.
} 